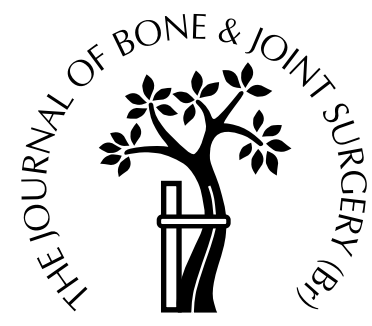

\title{
Surgical reconstruction of late pelvic post- traumatic nonunion and malalignment
}

\author{
D. C. Mears, J. Velyvis \\ From the University of Pittsburgh Medical Centre, Shadyside Hospital, Pittsburgh, USA
}

W e have retrospectively reviewed the clinical and radiological results in 204 consecutive adult patients who had surgical correction of 70 late posttraumatic pelvic nonunions and 134 malalignments. The deformed pelvises were subdivided into united (true), unstable, ununited, and partially stable malalignments with heterotopic bone. The principal complaints were of pain, pelvic instability, sitting imbalance, and apparent limb-length discrepancy. After surgery, 195 patients (96\%) achieved a primary union and $144(71 \%)$ had slight, intermittent or no pelvic pain, while pelvic instability was entirely eliminated. Overall, 131 patients $(64.2 \%)$ were extremely satisfied, $58(28.4 \%)$ were satisfied and $15(7.4 \%)$ were unsatisfied. After reconstruction of the malaligned pelvises, 67 results $(50 \%)$ were anatomical, $47(35 \%)$ were satisfactory and $20(15 \%)$ were unsatisfactory. For a pelvic nonunion with local osteopenia and malalignment, stabilisation of all three pelvic columns is recommended. True pelvic (united) malunions were the most satisfactorily realigned and had the fewest complications. Ununited and unstable malalignments, especially those with heterotopic bone, had the poorest corrections and the most neurological complications. A therapeutic alternative, by the local resection of a symptomatic bony prominence, and fixation in situ of a posterior pelvic nonunion, gives highly effective symptomatic relief with fewer complications. Despite this, many patients had persistent low back pain.

J Bone Joint Surg [Br] 2003;85-B:21-30.

Received 18 March 2002; Accepted 10 May 2002

D. C. Mears, MD, PhD, Consultant Orthopaedic Surgeon Greater Pittsburgh Orthopaedic Associates, 5820 Centre Avenue, Pittsburgh, Pennsylvania 15206-3753, USA.

J. Velyvis, MD, Resident

Division of Orthopaedic Surgery, Albany Medical Centre, 47 New Scotland Avenue, A366 Albany, New York 12208-3479, USA.

Correspondence should be sent to Dr D. C. Mears.

(C)2003 British Editorial Society of Bone and Joint Surgery doi:10.1302/0301-620X.85B1.13349 \$2.00
In the exceptional circumstance in which a fracture of the pelvis is complicated by a symptomatic nonunion or malunion, this usually occurs in unstable injury patterns which have been initially managed non-operatively or solely by external fixation. ${ }^{1-14}$ We have carried out a retrospective clinical study to analyse the results of the surgical management of 204 consecutive patients with late, post-traumatic pelvic nonunion and malalignment who were followed for between two and 20 years.

\section{Patients and Methods}

Between 1975 and 1997, the senior author (DM) treated 221 patients with post-traumatic symptomatic pelvic nonunion and malalignment. In patients with a pelvic fracture which failed to unite within six months of injury, the indications for surgery were pelvic pain, instability and various symptomatic deformities. The reconstructions were carried out at a mean of 2.4 years ( 0.5 to 15$)$ after the injury. The clinical data, collected prospectively after the definitive surgical procedure, were compiled and analysed retrospectively. Postoperatively, the patients were assessed clinically and radiologically at 6 and 12 weeks, 6 and 12 months, and annually thereafter. For 17 patients who had moved, a local orthopaedic surgeon undertook the clinical assessments and obtained the pelvic radiographs. We completed the remainder of the assessments either by telephone or by letter, which included our non-validated questionnaire.

After reconstruction, two patients died in the early postoperative period from myocardial infarction, four died as a result of comorbidity within two years and 11 were lost to follow-up. These 17 patients were eliminated from this review. In the remaining 114 men and 90 women with a mean age of 52 years ( 24 to 88 ), there were 70 pelvic nonunions and 134 malalignments. The mean follow-up was 8.7 years (2 to 20). The initial mechanism of injury was a roadtraffic accident in 117, a fall in 53 and an industrial injury in 34. Initially, $166(81 \%)$ were treated non-operatively or solely by external fixation and 35 underwent open reduction and internal fixation.

The initial fractures were classified (Table I) as stable type A, partially stable type B, and wholly unstable type C. There was also a type-D pattern of injury which represented an unstable disruption of the posterior pelvic ring with a 


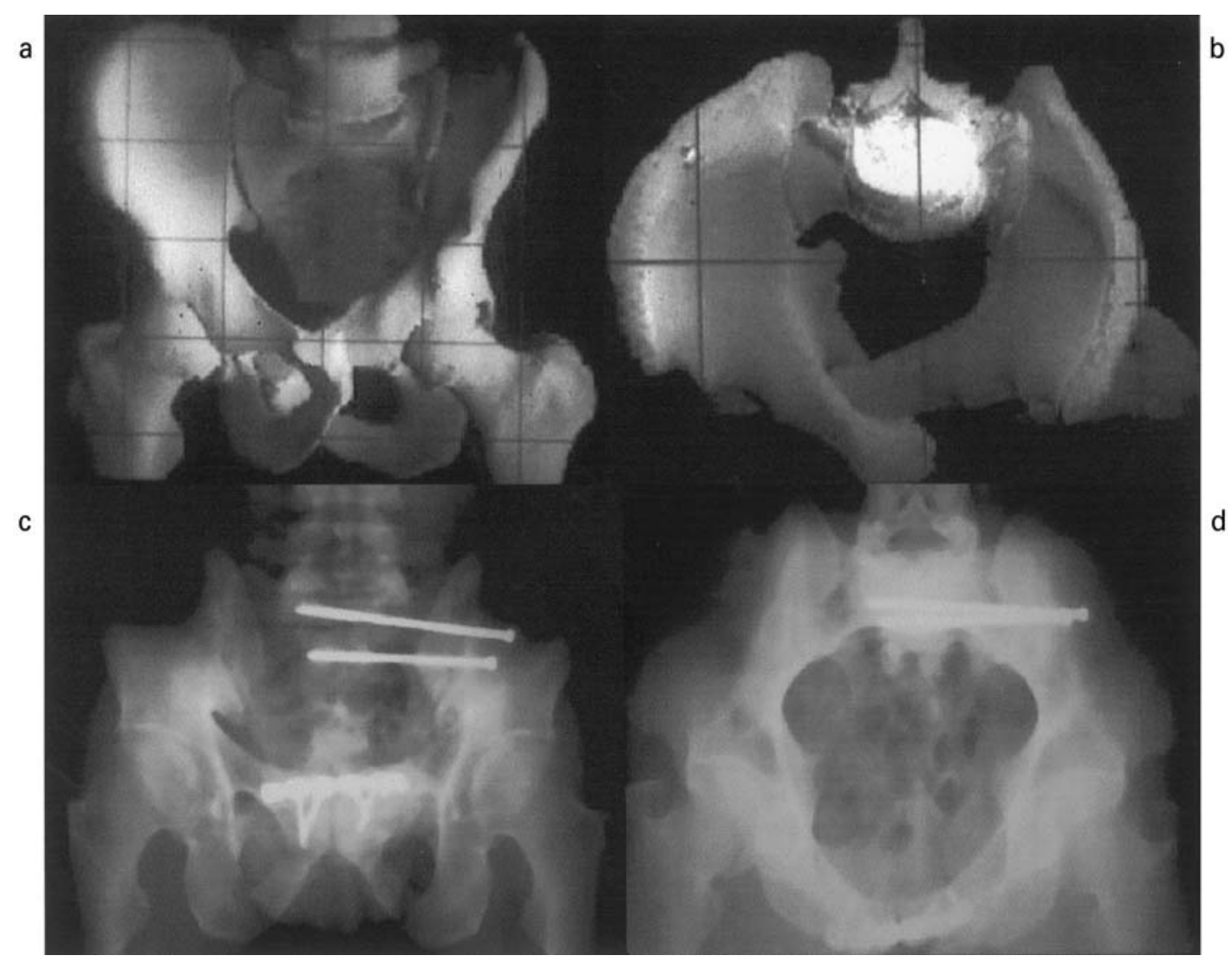

Fig. 1

A 41-year-old man presented with the principal complaint of an inability to void, due to a urethral obstruction secondary to a type 61-B2.1 internal rotational injury, which progressed to a type-II stable malalignment. Figures $1 \mathrm{a}$ and $1 \mathrm{~b}-\mathrm{Pre}-$ operative anterior and inlet three-dimensional CT showing internal rotation of the left hemipelvis with a left-sided sacral malunion and a locked left ramus in the right obturator foramen. Figures 1c and 1d-Postoperative outlet and inlet radiographs, taken one year later showing an anatomical reduction with two percutaneously introduced iliosacral screws and an anterior reconstruction plate. The patient could void without difficulty.

concomitant acetabular fracture. ${ }^{3,15-17}$ We classified late nonunion and malalignment as type I for an undeformed nonunion, type II for a stable (true) malalignment, type III for an unstable, ununited malalignment and type IV for a partially stable malalignment with incomplete stabilisation by callus and heterotopic bone.

Clinical assessment. The commonest complaint, disabling pelvic pain, which was inadequately controlled by simple analgesics and pain management (Table II), was assessed by its severity, site, and correlation with pelvic instability or neurological impairment. Instability was assessed by using an image intensifier. Sacroiliac pain was assessed by an intra-articular injection of lignocaine under CT guidance, and a technetium bone scan. ${ }^{18}$ Pain was an indication for surgery when it correlated with nonunion or a specific deformity. It was not an indication when it correlated with a lumbosacral plexopathy and dysaesthetic pain or a lower back problem. Only one patient, with urethral obstruction from a marked pelvic deformity was free from disabling pelvic pain (Fig. 1).

Of the 134 patients with type-I nonunion (70) or type-III ununited malalignment (64), $112(81 \%)$ complained of pelvic instability which would awaken them at night or when they undertook certain activities of daily living.

In 67 of the 134 patients (50\%) a frequent, symptomatic deformity and a surprisingly disabling condition was sitting imbalance, secondary to asymmetry of the ischial tuberosities. There was a vertical displacement in 22 patients $(16 \%)$ and a sagittal malrotation in 25 others (18\%). In five, a prominent posterior ilium from either a posterior displacement or a sagittal malrotation of the hemipelvis provoked discomfort with impingement on a chair or bed. There was a symptomatic limb-length discrepancy in 46 patients (34\%) with a vertical or sagittal malrotational deformity. Of the 20 patients with complex, bilateral, multiplanar rotational deformities, in nine this involved a pelvic obliquity with a complex rotational and vertical deformity at the lumbosacral junction. Initially, non-operative management had been used, including a shoe-raise for a limb-length discrepancy or a pelvic pad for sitting imbalance.

Radiological assessment. Routinely, anteroposterior (AP), inlet, and outlet radiographs, and a conventional pelvic CT scan had been obtained, and a three-dimensional CT scan for $128(96 \%)$ deformed pelvises. ${ }^{1,17-19}$ For the 112 patients 
Table I. Details of the initial posterior and anterior arch injury patterns (alphanumeric classification) for the 204 patients who underwent surgical reconstruction for late pelvic post-traumatic nonunion and malalignment

\begin{tabular}{|c|c|c|c|c|c|}
\hline $\begin{array}{l}\text { Initial } \\
\text { fracture } \\
\text { type }\end{array}$ & Subtype & Site & Number & $\begin{array}{l}\text { Total } \\
\text { number }\end{array}$ & Percentage \\
\hline \multicolumn{6}{|c|}{ CCF type 61 - pelvic ring fractures (posterior arch) } \\
\hline \multirow[t]{3}{*}{ A } & A1.1 & Ischial tuberosity & 1 & & \\
\hline & A 1.2 & Iliac wing & 1 & & \\
\hline & A 1.3 & Transverse displaced sacrum & 2 & 4 & 2.0 \\
\hline \multirow[t]{3}{*}{ B } & B1.1 & Unilateral external rotation sacroiliac joint (open book) & 3 & & \\
\hline & B1.2 & Unilateral internal rotation sacrum (lateral compression) & 2 & & \\
\hline & B1.3 & Bilateral (open book) & 2 & 7 & 3.5 \\
\hline \multirow[t]{9}{*}{$\mathrm{C}$} & $\mathrm{C} 1.1$ & Unilateral ilium & 34 & & \\
\hline & $\mathrm{C} 1.2$ & Unilateral sacroiliac joint & 32 & & \\
\hline & $\mathrm{C} 1.3$ & Unilateral sacrum & 29 & 95 & 46.5 \\
\hline & $\mathrm{C} 2.1$ & Complete ilium, contralateral incomplete & 25 & & \\
\hline & $\mathrm{C} 2.2$ & Complete sacroiliac joint, contralateral incomplete & 17 & & \\
\hline & $\mathrm{C} 2.3$ & Complete sacrum, contralateral incomplete & 21 & 63 & 31.0 \\
\hline & $\mathrm{C} 3.1$ & Bilateral complete extrasacral & 4 & & \\
\hline & $\mathrm{C} 3.2$ & Bilateral complete sacral, contralateral extrasacral & 19 & & \\
\hline & $\mathrm{C} 3.3$ & Bilateral complete sacral & 5 & 28 & 13.5 \\
\hline \multicolumn{6}{|c|}{ CCF type $62-$ concomitant acetabular fractures } \\
\hline \multirow[t]{10}{*}{$\mathrm{D}$} & $\mathrm{C} 1.1$ & B2.2 acetabular T-type juxtatectal (ununited) & 1 & & \\
\hline & $\mathrm{C} 1.2$ & B1.2a2 acetabular transverse infratectal - posterior wall (ununited) & 1 & & \\
\hline & & B1.3a2 acetabular transverse transtectal - posterior wall (united) & 1 & & \\
\hline & $\mathrm{C} 2.3$ & B1.3a2 acetabular transverse transtectal - posterior wall (ununited) & 1 & & \\
\hline & $\mathrm{C} 3.1$ & B1.3 acetabular transverse transtectal (united) & 1 & 3 & 3.0 \\
\hline & $\mathrm{C} 3.2$ & C2.2 both column, anterior column multifragmentary (united) & 2 & 7 & 3.5 \\
\hline & $\mathrm{C} 1$ to 3 & Ramus (unilateral or bilateral) & & 68 & 33.5 \\
\hline & $\mathrm{C} 4$ to 6 & Diastasis & & 115 & 56.5 \\
\hline & C7 to 9 & Ramus and diastasis & & 11 & 5.0 \\
\hline & $\mathrm{C} 10$ & Neither (unilateral or bilateral) & & 10 & 5.0 \\
\hline
\end{tabular}

with a complaint of pelvic instability, a manual stress test under image-intensifier control was undertaken with longitudinal traction and a rotational stress placed upon the pelvis. $^{18}$

For $149(73 \%)$ patients, the initial post-traumatic radiographs were available for classification of the fracture (Tables I and III). A quantitative, radiological characterisation of pelvic deformity (Fig. 2) used a modification of a technique which has been previously described. ${ }^{7,13}$ Conventional anatomical landmarks on the intact hemipelvis were compared with their positions on the deformed hemipelvis. Linear displacements of the hemipelvis were recorded in the superior, posterior, and medial vectors, and rotational and angular deformities were recorded in the transaxial, coronal, and sagittal planes. For bilateral pelvic deformities, the alignment of either hemipelvis before and after reconstruction was compared with the radiographs of an intact, normal pelvis.

Operative technique. Standard pelvic surgical exposures were used to debride the sites of nonunion, reapproximate the pelvic ring, obliterate bony defects with autologous bone graft, and apply stable internal fixation. ${ }^{18-22}$ Two external fixators were used after urological reconstructive procedures, which prohibited open symphyseal reductions. For a complex pelvic deformity, a multistaged procedure under one anaesthetic was used for anterior and posterior release in order to remove scar tissue, callus, and heterotopic bone. For a C-type multiplanar deformity, initially from a prone position, an extensive posterior release was carried out. Next, from a supine position, both the posterior and the anterior sites of malunion were released, reduced and stabilised. Finally, with the patient repositioned prone, the posterior pelvic ring was reduced and stabilised. For the 46 C-type and D-type injuries with a limb-length discrepancy, a supplementary curvilinear incision was made from the iliac crest to the inferior aspect of the lateral sacrum. This was to release the sacroiliac joint, adjacent sacral ala, and/or the posterior ilium, and to excise scarred iliolumbar, sacroiliac, sacrospinous, and sacrotuberous ligaments.

For five of the seven type-D patients with severe posttraumatic arthritis of the hip, a cementless, hybrid, or cemented total hip arthroplasty was carried out. This included obliteration of any acetabular defects with femoral head autograft. For two other type-D patients, with a concentrically malunited two-column acetabular fracture, and a secondary limb-length discrepancy (Fig. 3), a posterior iliac osteotomy was repositioned vertically and stabilised by internal fixation. For each, a concomitant type-IV ipsilateral transforaminal sacral malalignment was stabilised in situ.

During the last 11 years of this study, routine somatosensory evoked potential (SSEP) monitoring of the sciatic and pudendal nerves has been used, as well as image-intensifier assessment. $^{23-25}$ Throughout the study, prophylactic intravenous cephalosporin has been given for 48 to 72 hours after operation. For the initial 12 years of the study, thera- 


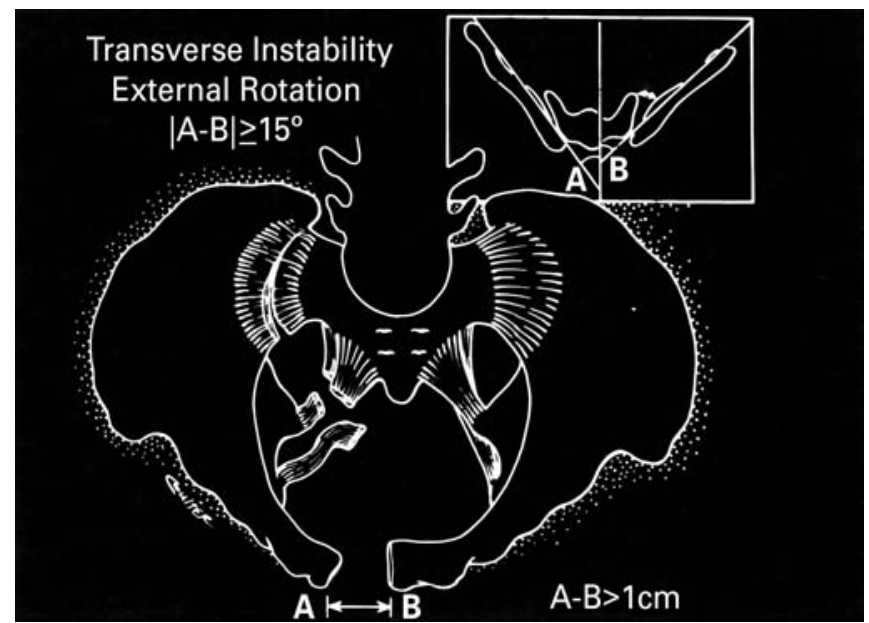

Fig. 2a

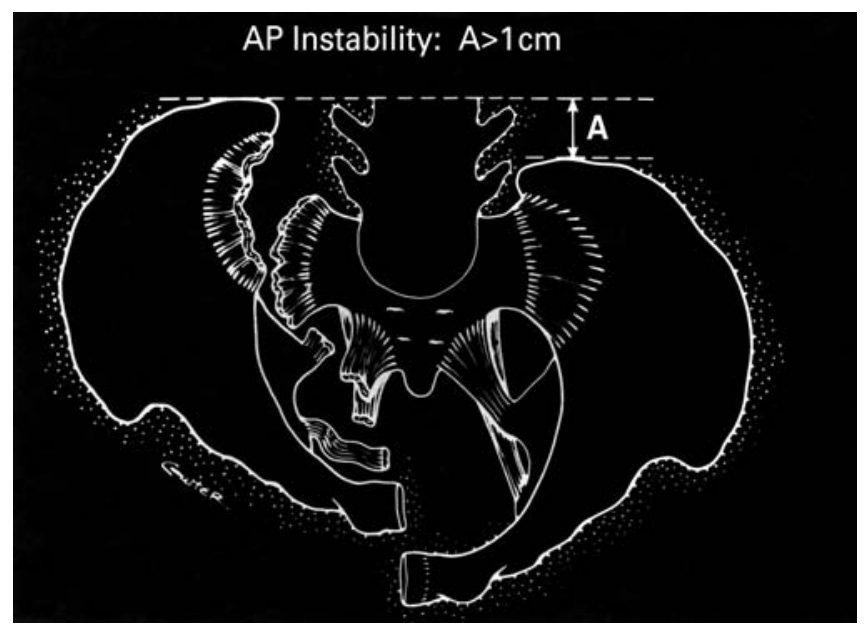

Fig. 2c

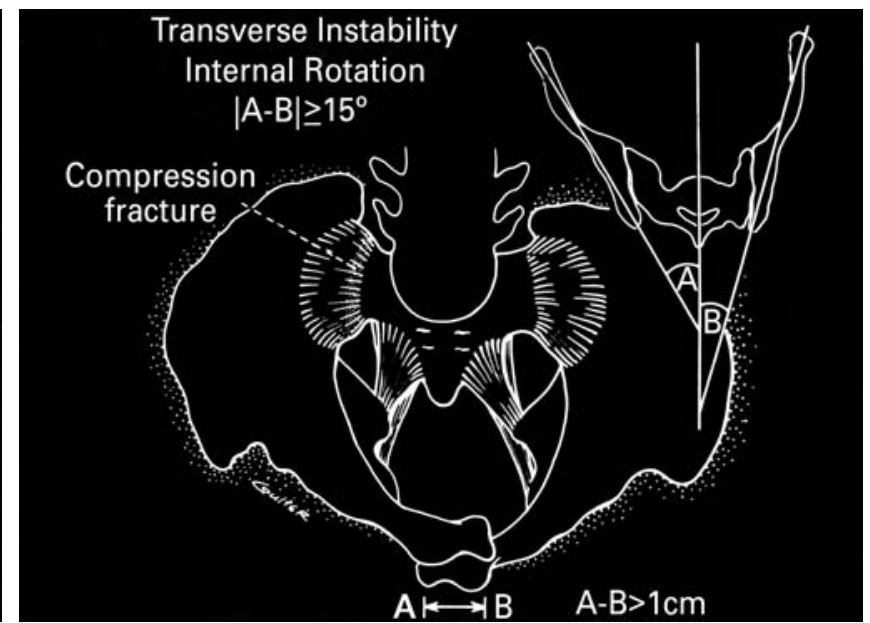

Fig. 2b

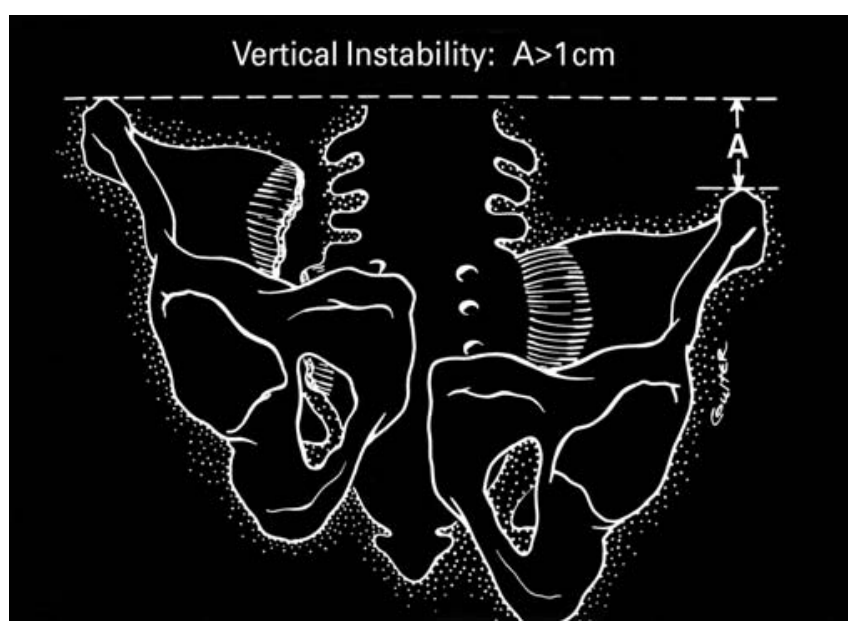

Fig. 2d

Schematic views showing a quantitative radiological assessment of selective rotational and linear deformities both for preoperative and postoperative assessment. Figure $2 \mathrm{a}-$ An external rotation deformity assessed on an inlet radiograph and transaxial CT. Figure $2 \mathrm{~b}-\mathrm{An}$ internal malrotation deformity assessed on an inlet radiograph and on CT. Figure $2 \mathrm{c}-\mathrm{An}$ AP deformity assessed on an inlet view. Figure $2 \mathrm{~d}-\mathrm{A}$ vertical deformity assessed on an AP or an outlet view.

peutic anticoagulation had been used for high-risk patients. Subsequently it was used routinely.

Follow-up assessment. All of the patients underwent clinical and radiological examinations at each follow-up. A standard, unvalidated questionnaire of the authors' design was used to assess patient satisfaction with respect to pain and physical and social function. The assessment of pain included its severity, duration, and the need for analgesics. Physical function was assessed by the walking distance and the need for walking aids. The assessment of social function included activities of daily living, employment, and other activities in the community. A highly satisfied patient was one with no or only minimal pain, no analgesic use, no requirement for walking aids, or the occasional use of a stick, and no limitation of activity. A satisfied patient was one with intermittent pain, no analgesic use, independent walking with or without a stick, and the restoration of inde- pendent activities of daily living. An unsatisfied patient was one with disabling pain, daily analgesic use, the need for a walking aid, and limited activities of daily living.

From the postoperative AP, inlet and outlet radiographs the correction of a pelvic deformity was characterised as: 1) anatomical, an anatomical correction in all three radiological views; 2) satisfactory, a residual deformity of less than 1 $\mathrm{cm}$ of vertical and/or posterior displacement and/or $15^{\circ}$ of rotational deformity in any plane; or 3) unsatisfactory, residual deformity of greater than $1 \mathrm{~cm}$ of vertical or posterior displacement and/or more than $15^{\circ}$ of rotational deformity.

\section{Results}

Union of the pelvic ring and relief of pelvic instability. A total of 195 patients $(96 \%)$ achieved union at a mean of 5.2 months (2 to 8 ). Of nine cases of persistent, exclusively 


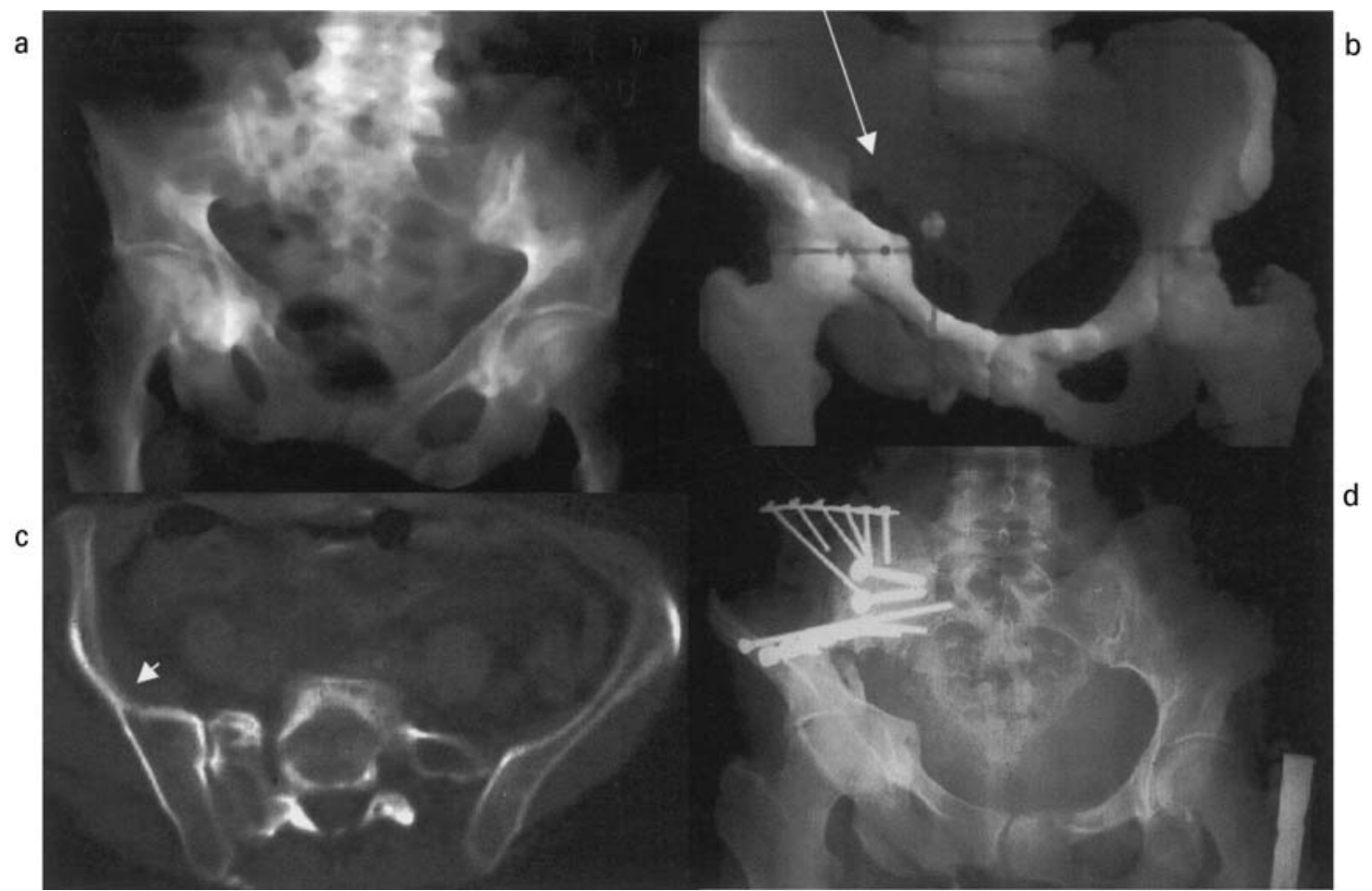

Fig. 3

A 42-year-old woman sustained an initial type 61-C3.2a2b4c3 displaced transforaminal sacral fracture which progressed to a type-III unstable malalignment. The patient had also had an initial ipsilateral type 62-C2.2 two-column acetabular fracture which healed with secondary congruity and was asymptomatic (type-II stable malalignment). She had a limb-length discrepancy of $4 \mathrm{~cm}$ and was frustrated by the use of a shoe-raise. The concomitant contralateral sacroiliac dislocation and bilateral fractures of the ramus had united uneventfully. Figures $3 a$ and $3 b$ - Preoperative AP radiograph (a) and three-dimensional CT anterior view, (b) showing vertical displacement of the right hemipelvis secondary to a sacral type-III unstable malalignment and an ipsilateral acetabular type-II stable malalignment. Figures $3 \mathrm{c}$ and $3 \mathrm{~d}$ - Preoperative transaxial CT (c) showing the right transforaminal sacral malaligned nonunion, and (d) a postoperative AP radiograph taken two years later showing fixation in situ of the sacrum with two cannulated screws. The arrows in Figures $3 \mathrm{~b}$ and $3 \mathrm{c}$ indicate the site of the osteotomy. A posterior osteotomy from the iliac crest to the greater sciatic notch, to correct the vertical displacement and limb-length discrepancy, was fixed with a plate as well as the cannulated screws. Before follow-up at two years, in a separate accident, she sustained a fracture of the left femur which was stabilised by an intramedullary nail.

type-C1 nonunion (4\%), six were transforaminal sacral (C1.3a2), one lateral sacral $(\mathrm{C} 1.3 \mathrm{a} 1)$ and two others were in the sacroiliac joint $(\mathrm{C} 1.2)$. To achieve union in these patients, between one and three additional procedures were needed. Two occurred in the 70 type-I $(2.9 \%)$, three in the 64 type-III (4.6\%), and four in the 27 type-IV (15\%) injuries. None arose in the 43 type-II malalignments. For the 112 patients with a preoperative complaint of pelvic instability, all of whom had more than $1 \mathrm{~cm}$ of displacement of a hemipelvis during the stress test, each had symptomatic relief.

Relief of pelvic pain. One year after surgery, 19 patients had no pelvic pain, 122 had slight or intermittent pain, and 57 had pain on walking which resolved with rest. Six patients had moderately severe pain, although all could walk (Table II). Three had iatrogenic lumbosacral plexopathies with dysaesthesiae. During the following year, the symptoms resolved in two. The other three experienced persistent pain which did not improve during the subsequent years of assessment.

Walking. One year after surgery, 93 patients walked normally and 66 had a slight limp, but did not use a stick.
Although all the remaining 45 patients could walk, 34 used a stick or a crutch for long walks and 11 were limited despite the use of a walking aid. These results did not change with the subsequent assessments (Table II).

Correction of pelvic deformity. There were 67 (50\%) anatomical reductions, 47 (35\%) satisfactory reductions, and 20 (15\%) unsatisfactory reductions (Tables III and IV). An anatomical reduction was universally achieved for each of the seven type-B pelvic fractures (Figs 1 and 4). For the C1 reconstructions, the degree of correction was more variable. Whereas posterior pelvic prominence was always corrected anatomically, the results for limb-length discrepancy, pelvic obliquity and sitting imbalance were variable. For example, limb-length discrepancy was anatomically or satisfactorily corrected in 38 patients $(87 \%)$ and unsatisfactorily corrected, with greater than $1 \mathrm{~cm}$ of persistent discrepancy, in six (13\%). For the complex, bilateral C3 rotational deformities, the correction of deformity was anatomical in ten patients $(48 \%)$, satisfactory in seven $(33 \%)$, and unsatisfactory in four (19\%). The seven D-type injuries showed four satisfactory, three unsatisfactory and no anatomical correc- 
Table II. Assessment of pain, walking and pelvic stability before and after surgical reconstruction of late pelvic post-traumatic nonunion and malalignment

\begin{tabular}{|c|c|c|c|c|}
\hline & \multicolumn{2}{|l|}{ Before } & \multicolumn{2}{|l|}{ After } \\
\hline & $\begin{array}{l}\text { Number } \\
\text { of patients }\end{array}$ & $\%$ & $\begin{array}{l}\text { Number } \\
\text { of patients }\end{array}$ & $\%$ \\
\hline \multicolumn{5}{|l|}{ Pain } \\
\hline None & 1 & 0.5 & 19 & 9.0 \\
\hline Slight, intermittent & 19 & 9.0 & 122 & 60.0 \\
\hline Slight with walking & 53 & 26.0 & 57 & 28.0 \\
\hline Constant with walking & 57 & 28.0 & 6 & 3.0 \\
\hline Severe, prevents walking & 73 & 36.0 & 0 & 0.0 \\
\hline \multicolumn{5}{|l|}{ Walking } \\
\hline Normal & 26 & 13.0 & 93 & 46.0 \\
\hline Limp, no stick & 54 & 26.0 & 66 & 32.0 \\
\hline Stick, crutch & 74 & 36.0 & 34 & 17.0 \\
\hline Limited walking & 50 & 25.0 & 11 & 5.0 \\
\hline No walking & 0 & 0.0 & 0 & 0.0 \\
\hline Pelvic instability & 112 & 55.0 & 0 & 0.0 \\
\hline
\end{tabular}

tions. A complex deformity could be unsatisfactorily corrected in more than one plane. Of the 20 unsatisfactory reductions, four were type-II (9\%), seven type-III (11\%), and nine type-IV (33\%) injuries.

Patient satisfaction. One year after their procedure, 131 patients (64\%) were extremely satisfied, 58 (28\%) satisfied, and $15(7.3 \%)$ unsatisfied (Tables III and IV). For the 134 patients with pelvic instability, $103(77 \%)$ were extremely satisfied, 31 (23\%) were satisfied, and none unsatisfied. For the nine patients with a persistent nonunion, when the satisfaction rating was reassessed at one year after the last procedure, the results improved from four satisfied and five unsatisfied patients to five extremely satisfied, three satisfied, and one unsatisfied.

After correction of the pelvic deformity of the 46 patients with C-type injuries and with symptomatic limb-length discrepancies, 27 (59\%) were extremely satisfied, 15 (33\%) satisfied, and four (8\%) were unsatisfied. Of the two patients with D-type injuries who achieved an unsatisfactory correction of a limb-length discrepancy, one was satisfied with the outcome and the other was not. Of 66 patients with symptomatic sitting imbalance, 43 (64\%) were extremely satisfied, 18 (28\%) were satisfied, and five (8\%) were unsatisfied (Table II). Two of the five unsatisfied patients subsequently underwent a resection of the more inferior ischial tuberosity and achieved an extremely satisfied outcome. Of the 37 patients with a major complaint from a complex rotational deformity or pelvic obliquity, including its cosmetic implications, 25 (67\%) were extremely satisfied, eight (22\%) satisfied, and four (11\%)

a

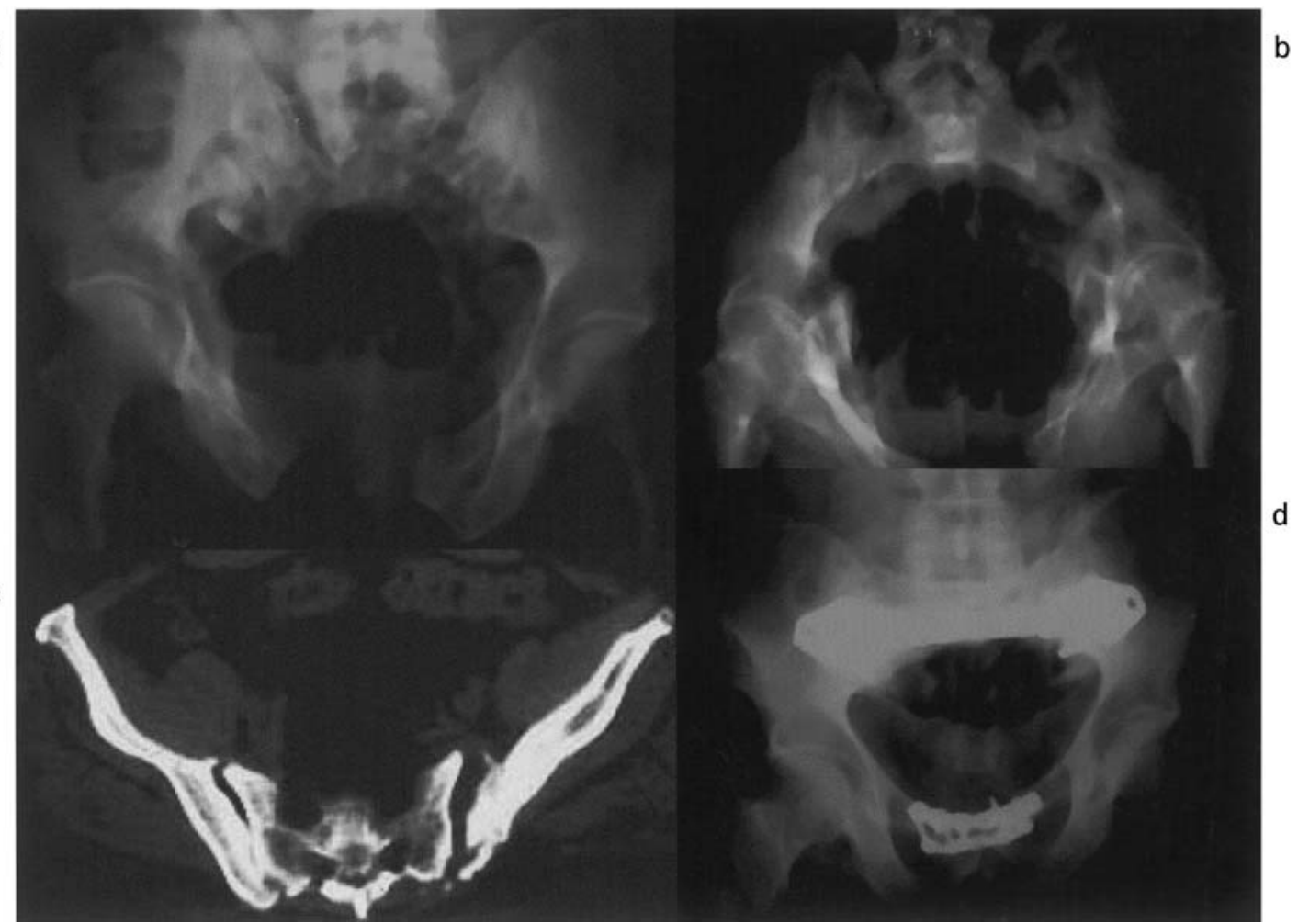

Fig. 4

A 35-year-old man who had sustained a type 61-B3,1a1b1c5 external rotation injury 14 years earlier, had after non-operative treatment progressed to a painful type-III unstable ununited malalignment. Figures $4 \mathrm{a}$ and $4 \mathrm{~b}-\mathrm{Preoperative} \mathrm{AP} \mathrm{(a)} \mathrm{and}$ inlet (b) radiographs showing a bilateral external rotational or open-book deformity with a diastasis of $10 \mathrm{~cm}$. Figures $4 \mathrm{c}$ and 4d - Preoperative CT (c) showing subluxation of the right and dislocation of the left sacroiliac joint and a postoperative AP radiograph (d) taken three years later showing satisfactory correction of the deformity. A double Cobra plate stabilises the posterior aspect of the pelvic ring and two symphyseal plates secure the symphysis pubis. 
Table III. Surgical indications, surgical results, and late outcomes one year after surgical reconstruction for type-II, type-III and type-IV malalignments. Many patients presented with two or more complaints

\begin{tabular}{|c|c|c|c|c|c|c|c|c|c|}
\hline \multirow{2}{*}{$\begin{array}{l}\text { Initial } \\
\text { fracture } \\
\text { type }\end{array}$} & \multirow{2}{*}{$\begin{array}{l}\text { Number } \\
\text { of } \\
\text { patients }\end{array}$} & \multirow[b]{2}{*}{ Complaint } & \multirow{2}{*}{$\begin{array}{l}\text { Number } \\
\text { of } \\
\text { patients }\end{array}$} & \multicolumn{3}{|c|}{ Correction of deformity } & \multicolumn{3}{|c|}{ Patient satisfaction } \\
\hline & & & & Anatomical & Satisfactory & Unsatisfactory & $\begin{array}{l}\text { Extremely } \\
\text { satisfactory }\end{array}$ & Satisfactory & Unsatisfactory \\
\hline A & 1 & Pain & 1 & 1 & 0 & 0 & 1 & 0 & 0 \\
\hline \multirow[t]{4}{*}{ B } & 7 & Pain & 6 & & & & 6 & 0 & 0 \\
\hline & & Pelvic instability & 6 & 6 & 0 & 0 & 6 & 0 & 0 \\
\hline & & Simple rotational deformity & 7 & 7 & 0 & 0 & 7 & 0 & 0 \\
\hline & & Kinked urethra & 1 & 1 & 0 & 0 & 1 & 0 & 0 \\
\hline \multirow[t]{8}{*}{$\mathrm{C}$} & 119 & Pain & 119 & & & & 72 & 21 & 26 \\
\hline & & Pelvic instability & 61 & & & & 43 & 18 & 0 \\
\hline & & Sitting imbalance & 66 & 10 & 44 & 12 & 43 & 18 & $5 *$ \\
\hline & & Leg-length discrepancy & 44 & 10 & 28 & 6 & 27 & 14 & $3 \dagger$ \\
\hline & & $\begin{array}{l}\text { Complex rotational } \\
\text { deformity }\end{array}$ & 21 & 10 & 7 & 4 & 15 & 4 & 2 \\
\hline & & Pelvic obliquity & 9 & 3 & 5 & 1 & 6 & 2 & 1 \\
\hline & & Posterior iliac prominence & 5 & 5 & 0 & 0 & 5 & 0 & 0 \\
\hline & & Standing imbalance & 1 & 1 & 0 & 0 & 1 & 0 & 0 \\
\hline \multirow[t]{6}{*}{ D } & 7 & Pain & 7 & & & & 7 & 0 & 0 \\
\hline & & Pelvic instability & 3 & & 0 & 0 & 3 & 0 & 0 \\
\hline & & Sitting imbalance & 1 & 0 & 0 & 1 & 0 & 0 & $1 \ddagger$ \\
\hline & & Leg-length discrepancy & $2 \dagger$ & 0 & 0 & 2 & 0 & 1 & 1 \\
\hline & & $\begin{array}{l}\text { Complex rotational } \\
\text { deformity }\end{array}$ & 7 & 0 & 4 & 3 & 4 & 2 & 1 \\
\hline & & $\begin{array}{l}\text { Symptomatic hip (total hip } \\
\text { arthroplasty) }\end{array}$ & 5 & & & & 5 & 0 & 0 \\
\hline
\end{tabular}

*includes seven patients who underwent one to three additional procedures before achieving a favourable correction

$\dagger$ includes two patients with persistent use of a shoe lift

łafter a subsequent palliative correction with a resection of the ischial tuberosity there was an extremely satisfactory outcome

Table IV. Late outcome for patient satisfaction and correction of deformity one year after surgical reconstruction of late pelvic post-traumatic nonunion and malalignment, by number and percentage

\begin{tabular}{|c|c|c|c|c|c|c|c|c|}
\hline & & \multirow{2}{*}{$\begin{array}{l}\text { Number } \\
\text { of patients }\end{array}$} & \multicolumn{3}{|l|}{ Patient satisfaction } & \multicolumn{3}{|c|}{ Correction of deformity } \\
\hline & & & Extremely satisfactory & Satisfactory & Unsatisfactory & Anatomical & Satisfactory & Unsatisfactory \\
\hline I & Nonunion & 70 & $55(79)$ & $15(21)$ & 0 & - & - & - \\
\hline II & United malalignment & 43 & $29(67)$ & $13(30)$ & $1(2)$ & $23(53)$ & $16(37)$ & $4(9)$ \\
\hline III & Ununited malalignment & 64 & $42(66)$ & $14(21)$ & $8(13)$ & $30(47)$ & $27(42)$ & $7(11)$ \\
\hline \multirow[t]{2}{*}{ IV } & $\begin{array}{l}\text { Partially united } \\
\text { malalignment }\end{array}$ & 27 & $5(18)$ & $16(59)$ & $6(22)$ & $14(52)$ & $4(15)$ & $9(33)$ \\
\hline & Subtotal for types II to IV & 134 & $76(57)$ & $43(32)$ & $15(11)$ & $67(50)$ & $47(35)$ & $20(15)$ \\
\hline
\end{tabular}

were unsatisfied. For the five patients with a major complaint of posterior iliac prominence, five others with a painful hip because of post-traumatic arthritis, and one with an obstructed urethra, all were extremely satisfied after the reconstruction.

Of the 43 patients with a type-II stable, united malalignment, 29 were extremely satisfied, 13 satisfied, and one was unsatisfied. Of the 64 patients with a type-III unstable, ununited malalignment, 42 were extremely satisfied, 14 satisfied, and eight unsatisfied. Of the 27 patients with a typeIV partially stable malalignment because of heterotopic bone and fracture callus, five were extremely satisfied, 16 satisfied, and six were unsatisfied (Table IV).

Postoperative complications. Two patients died from myocardial infarction between two and 60 days after surgery. Three cases of deep wound infection resolved after a single surgical debridement and administration of intravenous antibiotics. After the correction of a pelvic deformity, palsy of the sciatic nerve or injury to the lumbosacral plexus developed in eight patients (3.9\%). In five it completely resolved within six months while in three others it persisted indefinitely. Six of the eight (75\%) cases of palsy of the sciatic nerve occurred with type-IV malalignment (Fig. 5) and two (25\%) with type-III malalignment. Five of the eight patients underwent intraoperative SSEP monitoring. Seven patients had a postoperative pulmonary embolism and 14 others had a symptomatic deep-vein thrombosis of the lower limb. In all these resolved after therapeutic anticoagulation. There were nine cases of persistent nonunion.

Between one and two years after the procedure, 103 (51\%) of the 204 patients complained of low back pain. The pain was mild and intermittent in 60 patients (29\%), moder- 


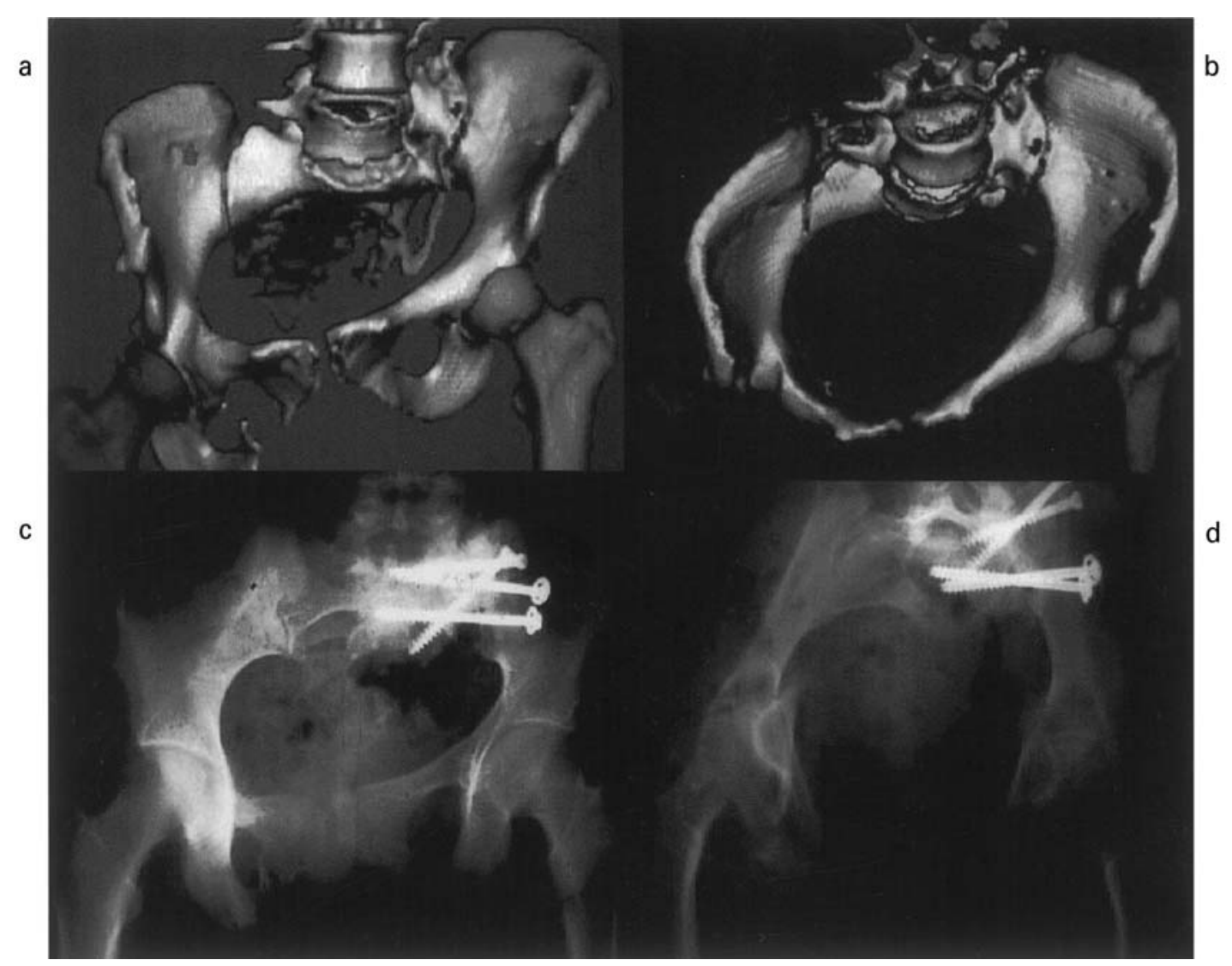

Fig. 5

A 28-year-old woman presented with a type-IV equivocally stable malalignment. Two years earlier she had sustained a type $61-\mathrm{C} 1.3 \mathrm{a} 1 \mathrm{c} 2$ injury to the lateral sacrum and contralateral rami with uncorrected vertical, posterior and multiplanar rotational deformity. Figures $5 \mathrm{a}$ and $5 \mathrm{~b}$ - Preoperative anterior (a) and superior (b) three-dimensional views showing the superior and posterior linear displacement of the left hemipelvis with associated sagittal and internal malrotation. Extensive heterotopic bone is seen inferior to the left greater sciatic notch and pelvic floor which, characteristically, is poorly seen on plain radiographs. Figures $5 \mathrm{c}$ and $5 \mathrm{~d}$ - Postoperative AP (a) and inlet (d) views taken two years later showing a satisfactory correction of the deformity. The vertical and posterior deformities are well corrected although the sagittal and internal malrotation persists. There are three iliosacral screws and a sacral lag screw. In the presence of such heterotopic bone, despite a considerable risk for a neurological injury, an incomplete correction of the deformity can be anticipated.

ate and persistent in $36(18 \%)$, and severe with physical incapacity in seven (3\%). A total of 64 patients $(62 \%)$ with persistent low back pain had sustained a traumaticallyinduced lumbar spinal injury with their pelvic fracture. This included fracture of a transverse process in 45 patients (70\%), an undisplaced fracture of the body of L4 or L5 in seven $(11 \%)$, a unilateral facet fracture in six $(9 \%)$, a bilateral facet fracture in three (5\%), and spondylolisthesis in three others (5\%). It was often difficult or impossible to distinguish lower lumbar from posterior pelvic pain. Excluding associated low back pain, the number of complications was 43 with an incidence of $21 \%$, including 16 unsatisfactory reductions.

\section{Discussion}

Symptomatic post-traumatic pelvic nonunion and malalignment are uncommon. ${ }^{2,13,14,26-28}$ A patient who survives these life-threatening injuries does not usually wish further corrective surgery unless the symptoms are disabling. Many pelvic deformities are well tolerated by the compensatory mobility of the lumbosacral spine and hips. More than $99 \%$ of our patients presented with disabling pelvic pain. After surgery, $65 \%$ were extremely satisfied with the degree of relief from pain, $16 \%$ were satisfied and $17 \%$ were unsatisfied, although there was usually some residual, mild pelvic or low back pain. For the preoperative assessment, the distinction of true pelvic pain from mechanical low back pain or dysaesthetic pain of neurological origin is crucial, but the available diagnostic tests for such an assessment are not wholly reliable. Elimination of the unpleasant and disabling sense of pelvic instability which affected $81 \%$ of the patients was one of the most striking observations of our study. While the assessments of patient satisfaction and outcome were crude in comparison with current outcome evaluations, they are indicative of the methods which were available at the beginning of our study. Unfortunately, there was no practical way to incorporate retrospectively the more elaborate recently validated techniques. 


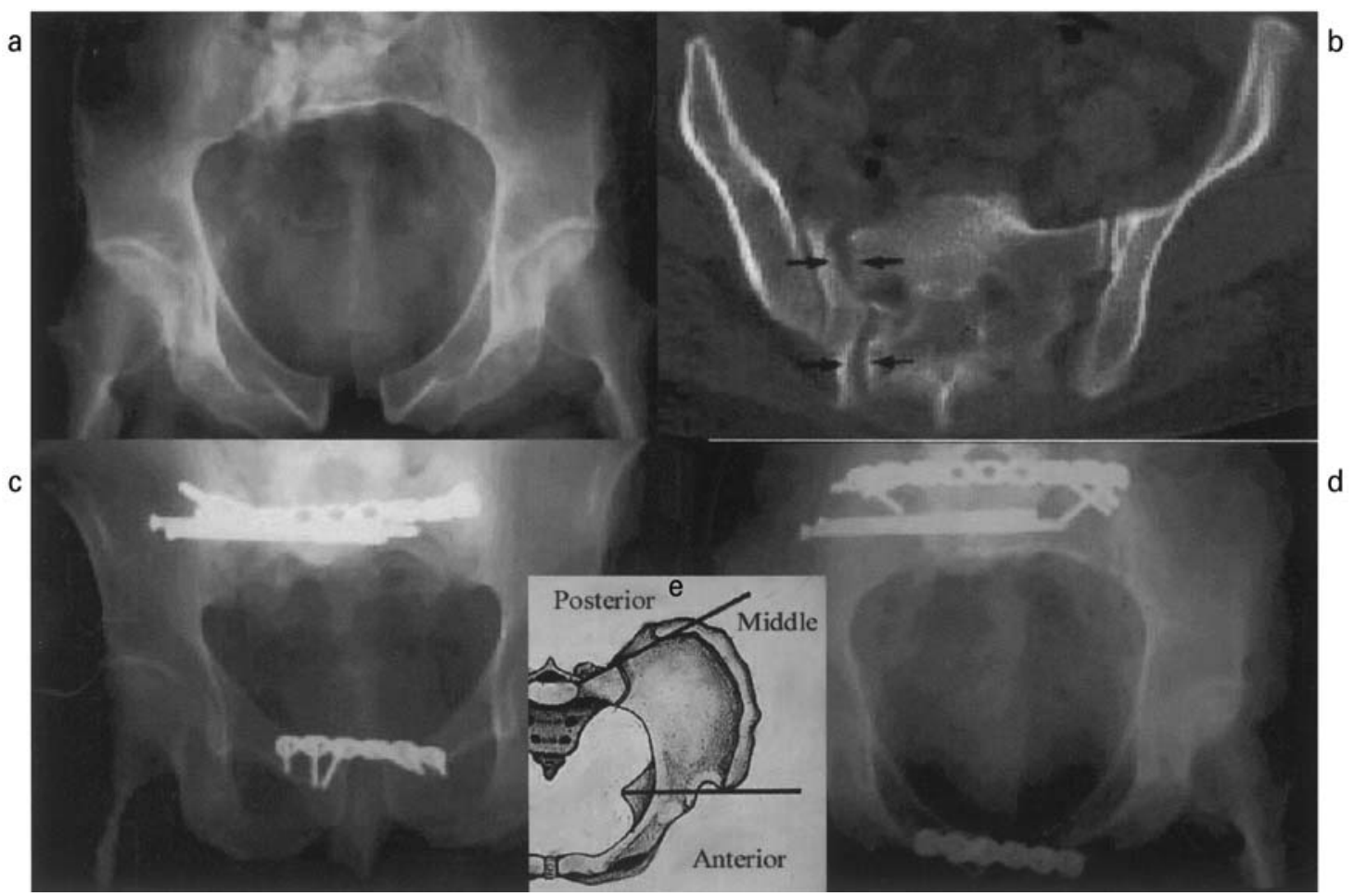

Fig. 6

Two years after this 48-year-old man had sustained a type C1.3a2c5 right transforaminal sacral fracture which was treated conservatively, he presented with a painful unstable nonunion. Figures $6 \mathrm{a}$ and $6 \mathrm{~b}-\mathrm{A}$ preoperative inlet view (a) with an anterior diastasis of $4 \mathrm{~cm}$ and (b) a preoperative CT scan showing the malaligned sacral nonunion. Figure $6 \mathrm{c}-\mathrm{A}$ postoperative AP view three years after fixation showing a persistent diastasis of $2 \mathrm{~cm}$. The patient was asymptomatic and extremely satisfied with the outcome and had a united posterior pelvis. Figure $6 \mathrm{~d}-\mathrm{A}$ postoperative inlet radiograph taken three years later showing an in situ stabilisation of the three columns. A nine-hole reconstruction plate secures the posterior column along the posterior sacral surface. Two cannulated iliosacral screws immobilise the middle column including the sacroiliac joint and the $\mathrm{S} 1$ vertebral body. A six-hole reconstruction plate immobilises the anterior column at the symphysis pubis. Figure $6 \mathrm{e}-\mathrm{A}$ schematic view showing the three pelvic columns available for fixation.

Nine cases of persistent nonunion of type-C fractures involved primarily the sacral transforaminal zone with osteopenia, comminution, fracture gaps and the proximity of sacral nerve roots. Each of these early cases involved two sites of pelvic fixation, such as a posterior pelvic plate or an iliosacral screw, combined with a symphyseal plate. ${ }^{21}$ Later, we considered the pelvis as having 'three columns, ${ }^{7,18}: 1$ ) the symphysis and rami; 2) the posterior column, sacral bodies, and the interposed sacroiliac joints; and 3) the posterior sacroiliac ligaments interposed between the posterior sacral elements and the iliac spines. All of the subsequent 112 C-type nonunions with three-column fixation united uneventfully (Fig. 6). For nonunion of adjacent superior and inferior pubic rami, fixation of both rami is recommended.

As regards the correction of pelvic malalignment, all patients with a posterior iliac prominence, standing imbalance, and an obstructed urethra had successful correction. Sitting imbalance was less uniformly corrected, with only $64 \%$ of patients being extremely satisfied. Usually, disfigurement secondary to a multiplanar bilateral deformity was not perfectly corrected. Nevertheless, after a partial correction many patients were highly satisfied with their improved appearance in clothes. For a patient with persistent sitting imbalance after an inadequate correction of a complex deformity, a palliative resection of the ischial tuberosity on the intact hemipelvis was uniformly successful. For a patient with a type-III or type-IV deformity and concomitant comorbid medical problems, a palliative procedure such as a resection of a symptomatic bony prominence or a corrective femoral shortening or lengthening of an apparent limb-length discrepancy, merits consideration. This eliminates the considerable risk of complications after major pelvic reconstruction.

Isolated unilateral or bilateral external and internal rotational deformities (Figs 1 and 4), were technically the easiest corrections (Table III) while sagittal and coronal deformities were much more difficult. Posterior displacement was the simplest linear correction, while vertical displacement was the most difficult. Bilateral C-type multiplanar deformities were the most complex corrections, although many patients were grateful for the cosmetic improvement after a partial realignment. In six of the eight cases of iatrogenic palsy of the sciatic nerve $(75 \%)$ arising in type-IV malalignment, a reduction of a transforaminal sacral C1.3 injury complicated by heterotopic bone in the pelvic floor, was likely to cause a neurological injury. This 
is despite the use of intraoperative SSEP monitoring. Even massive heterotopic bone in the pelvic floor may not be visible on a plain radiograph, although it is readily apparent on CT and especially, three-dimensional CT (Fig. 5). Subsequently, for each of three patients with an ununited C1.3 transforaminal malalignment, a stabilisation in situ of the nonunion and a corrective osteotomy of the posterior ilium (Fig. 3) were carried out without neurological complication.

Despite partial correction of the deformity, the seven patients with a type-D injury achieved union uneventfully. Five of seven patients with post-traumatic degenerative arthritis of a hip in whom the pelvic reconstruction included a total hip arthroplasty, were extremely satisfied. This correlates well with the excellent relief from pain and durable performance of the arthroplasty which is an established method of treatment of this situation. ${ }^{1,29}$

No benefits in any form have been received or will be received from a commercial party related directly or indirectly to the subject of this article.

\section{References}

1. Mears DC, Rubash HE. Pelvic and acetabular fractures. Thorofare, etc: Slack Incorporated, 1986

2. Pennal GF, Massiah KA. Nonunion and delayed union of fractures of the pelvis. Clin Orthop 1980;151:124-9.

3. Tile M. Fractures of the pelvis and acetabulum. 2nd edition. Baltimore: Williams and Wilkins, 1994:66-101,224-5.

4. Bosch U, Pohlemann T, Haas N, Tscherne H. Classification and management of complex pelvic trauma. Unfallchirurg 1992;95:189-96.

5. Dean Cole J, Blum DA, Ansel LJ. Outcome after fixation of unstable posterior pelvic ring injuries. Clin Orthop 1996;329:160-79.

6. Dujardin FH, Hossenbaccus M, Duparc F, Biga N, Thomine JM. Long-term functional prognosis of posterior injuries in high-energy pelvic disruption. J Orthop Trauma 1998;12:145-50.

7. Mears DC. Management of pelvic pseudarthroses and pelvic malunion. Orthopade 1996;25:441-8

8. Miranda MA, Riemer BL, Butterfield SL, Burke CJ 3rd. Pelvic ring injuries: a long term functional outcome study. Clin Orthop 1996;329:152-9.

9. Tile M. Pelvic ring fractures: should they be fixed? J Bone Joint Surg [Br] 1988;70-B:1-12.

10. Tornetta P III, Dickson K, Matta JM. Outcome of rotationally unstable pelvic ring injuries treated operatively. Clin Orthop 1996;329:147-51.
11. Van den Bosch EW, Van der Kleyn R, Hogervorst M, Van Vugt AB. Functional outcome of internal fixation for pelvic ring fractures. J Trauma 1999;47:365-71.

12. Lindahl J, Hirvensalo E, Bostman O, Santavirta S. Failure of reduction with an external fixator in the management of injuries of the pelvic ring: long-term evaluation of 110 patients. J Bone Joint Surg [Br] 1999;81-B:955-62.

13. Matta JM, Dickson KF, Markovich GD. Surgical treatment of pelvic nonunions and malunions. Clin Orthop 1996;329:199-206.

14. Vanderschot P, Daenens K, Broos P. Surgical treatment of post-traumatic pelvic deformities. Injury 1998;29:19-22.

15. Orthopaedic trauma association committee for coding and classification. Fracture and dislocation compendium. J Orthop Trauma 1996;10 Suppl 1:v-ix:1-154.

16. Muller ME, Allgower M, Schneider R, Willenegger $H$. Manual of in ternal fixation. 3rd edition. Berlin: Springer-Verlag, 1991.

17. Pennal GF, Tile M, Waddell JP, Garside H. Pelvic disruption: assessment and classification. Clin Orthop 1980;151:12-21.

18. Mears DC, Durbhakula SM. Fractures and dislocations of the pelvic ring. In: Chapman, MW, ed. Chapman's orthopaedic surgery. Philadelphia: Lippincott, Williams \& Wilkins, 2001:531-85.

19. Mears DC, Ward AJ, Wright MS. The radiological assessment of pelvic and acetabular fractures using three-dimensional computed tomography. Int J Orthop Trauma 1992;2:196-207.

20. Matta JM. Surgical approaches to the acetabulum and pelvis. In: Chapman, MW, ed. Chapman's orthopaedic surgery. Philadelphia: Lippincott, Williams \& Wilkins, 2001:17-28

21. Mears DC, Capito CP, Delleuw H. Posterior pelvic disruptions managed by the use of the Double Cobra Plate. Instr Course Lect 1988;37:143-50.

22. Matta JM. Regarding safe and effective placement of iliosacral screws J Orthop Trauma 1996;10:514.

23. Baumgaertner MR, Wegner D, Booke J. SSEP monitoring during pelvic and acetabular fracture surgery. J Orthop Trauma 1994;8:127-33.

24. Helfet DL, Koval KJ, Hissa EA, et al. Intraoperative somatosensory evoked potential monitoring during acute pelvic fracture surgery. $J$ Orthop Trauma 1995;9:28-34.

25. Vrahas M, Gordon RG, Mears DC, Krieger D, Sclabassi RJ. Intraoperative somatosensory evoked potential monitoring of pelvic and acetabular fractures. J Orthop Trauma 1992;6:50-8.

26. Ebraheim NA, Biyani A, Wong F. Nonunion of pelvic fractures. $J$ Trauma 1998;44:202-4.

27. Tornetta P III, Matta JM. Outcome of operatively treated unstable pelvic ring disruptions. Clin Orthop 1996;329:186-93.

28. Letournel E. Diagnosis and treatment of nonunions and malunions of acetabular fractures. Orthop Clin North Am 1990;21:769-88.

29. Mears DC, Velyvis JH. Primary total hip arthroplasty after acetabular fracture. J Bone Joint Surg [Am] 2000;82-A:1328-53. 